\title{
Análise comparativa do estresse oxidativo de espermatozoides da cauda do epidídimo e do ejaculado de garanhões
}

Priscilla Nascimento Guasti", Laíza Sartori de Camargo, Patricia de Mello Papa, Rubia Alves Schmith, Luis Fernando Mercês Chaves Silva, Luiz Roberto Pena Andrade Junior, Juliana Pedroso Mendes, Camila Paula Freitas-Dell’Aqua, Frederico Ozanam Papa

Universidade Estadual Paulista(UNESP), Botucatu, SP, Brasil

*Autor correspondente

e-mail: priguasti@gmail.com

\section{Resumo}

O equino é o único mamífero que possui uma relação positiva entre o estresse oxidativo e a funcionalidade espermática, e este efeito paradoxal possui influência direta na capacidade fertilizante dos espermatozoides. As células espermáticas do epidídimo não possuem contato com o plasma seminal, o qual possui importantes propriedades antioxidantes que contribuem para a proteção contra as espécies reativas ao oxigênio (EROS). O objetivo deste estudo foi avaliar o estresse oxidativo de espermatozoides colhidos da cauda do epidídimo e do ejaculado de equinos. Foi coletado um ejaculado de 11 garanhões. Após uma semana, os animais submetidos à orquiectomia bilateral e os espermatozoides da cauda do epidídimo foram coletados por fluxo retrógrado. $\mathrm{O}$ estresse oxidativo foi avaliado por meio da análise da produção de $\mathrm{H}_{2} \mathrm{O}_{2}$ intracelular com a sonda fluorescente carboxi-H2DCFDA (Molecular Probes) e análise da peroxidação lipídica com a sonda fluorescente C11-BODYPY (Molecular Probes), utilizando citometria de fluxo (LSR II Fortessa, BD Biosciences). A taxa de produção de $\mathrm{H}_{2} \mathrm{O}_{2}$ e peroxidação lipídica foram testadas quanto à normalidade com o teste de Kolmorov-Smirnov; os dados paramétricos foram analisados pelo teste t de Student não pareado e os não paramétricos pelo teste de Mann-Whitman, considerando o valor de $\mathrm{P}<0,05$ como significativo. Os dados estão apresentados como média \pm SEM. A produção de $\mathrm{H}_{2} \mathrm{O}_{2}$ intracelular dos espermatozoides do ejaculado $(28,02 \pm 7,2)$ foi significativamente maior em comparação aos espermatozoides da cauda do epidídimo $(12,85 \pm 4,08)$. Da mesma forma, os espermatozoides do ejaculado $(32,90 \pm 8,04)$ apresentaram maior índice de peroxidação lipídica da membrana plasmática em comparação aos espermatozoides colhidos da cauda do epidídimo $(12,95 \pm 0,97 ; \mathrm{P}<0,05)$. No ducto epididimário, as células espermáticas se encontram em um estado de quiescência metabólica e são ativadas somente no momento da ejaculação, na qual os componentes do plasma seminal contribuem com o início desta ativação do metabolismo espermático. Ainda, o espermatozoide equino é altamente dependente da produção de ATP via mitocôndrias, e como 
consequência do alto potencial mitocondrial, grandes quantidades de EROS são geradas, indicando alto metabolismo celular. Apesar do plasma seminal apresentar uma série de enzimas que possuem atividades captadoras (scavenger) de EROS, a alta atividade metabólica dos espermatozoides ejaculados se sobrepõe naturalmente as suas propriedades antioxidantes. Desta forma, foi possível concluir que os espermatozoides do epidídimo possuem menor estresse oxidativo em comparação aos espermatozoides do ejaculado, devido ao baixo metabolismo celular durante o armazenamento na cauda do epidídimo.

Palavras-chave: Peroxidação lipídica. Espécies reativas ao oxigênio. Equino.

Agradecimentos: à Fundação de Amparo À Pesquisa do Estado de São Paulo (FAPESP) pelo apoio financeiro. 